difunden rápidamente. Uno de los numerosos folletos políticos publicados ese año en Cádiz lleva por título: Un español liberal a los llama. dos liberales y serviles. Más tarde una comedia: Liberales y serviles. $\mathrm{Y}$ en 1814, en Cádiz también, el primer periódico: El Liberal ${ }^{12}$.

Por último, no tardan en aparecer dos nuevas expresiones: liberalismo y su opuesto servilismo. En el Diario Militar, Politico y Mercantil de la ciudad de Tarragona, de 21 de noviembre de 1813 , hay un artículo sobre los serviles y liberales que termina con estos versos:

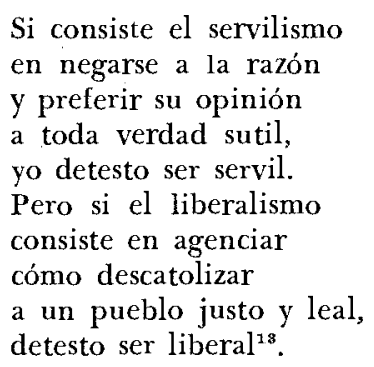

La trayectoria es clara. Y una vez más queda reflejada en El Español de Blanco White. Allí no aparece servil hasta mediados de 1813: en ese mismo año aún se dice liberalidad; en 1814 , liberalismo. El valor documental de la publicación de Blanco, que por su naturaleza tenía que estar al corriente y hacerse eco del nuevo lenguaje de las Cortes, se acrece por la circunstancia de vivir su autor en Inglaterra y tener contacto con diversos medios políticos: Lord Holland por una parte, Southey y la Quarterly Review por otra ${ }^{14}$. Si las expresiones acuñadas en Cádiz no hubieran sido realmente nuevas, en Inglaterra al menos, bien lo hubiera notado Blanco, tan atento siempre a los matices del vocabulario político inglés ${ }^{15}$.

Princeton University.

VICENTE LLORÉNS

\title{
APOSTILLAS A UN ARTICULO SOBRE EL ROMANCERO
}

En su comentario al libro de $\mathbf{R}$. Menéndez Pidal, Diego Catalán y Álvaro Galmés, Cómo vive un romance (Madrid, 1954), J. Horrent ( $L R$, $11,1957,379-394)$ expresa su discrepancia en cuanto a ciertas interpreta-

12 M. Gómez fmaz, Los periódicos durante la Guerra de la Independencia, Madrid, 1910 , p. 203. El folleto y la comedia, en la lista de obras prohibidas o mandadas recoger por la Inquisición en 1815 .

18 Ibid., p. 116.

34 Southey, que fue, según el Oxford English Dictionary, el primero en aplicar el nuevo sentido de liberal a la política inglesa (en un artículo de la Quarterly Review de abril de 1816 ), no emplea aún entonces el vocablo britanizado, sino subrayándolo en su forma española: "These are the personages for whose sake the continuance of the Alien Bill has been opposed by the British Liberales". En otro ejemplo (que cita el mismo diccionario) de 1823 , ya dice Liberals.

15 Blanco fue el introductor en español de una expresión que no prosperó en España, pero si en Hispanoamérica: vocero, neologismo deliberado con el cual quiso traducir el parlamentario speaker. 
ciones de detalle y de principio. El romance de la Boda estorbada "no debe de ser muy antiguo", puesto que se lo desconoce en varias regiones arcaizantes y su tradición revela gran fijeza. Su evidente origen -el romance del Conde Dirlos- hace pensar a Horrent que en la versión original el encuentro de la Condesa, como en el Dirlos tradicional, es con un vaquero y una manada de vacas (no con un pastor de caballos, mulas u otros animales). A la misma conclusión me llevó, hace algunos años, el texto de una canción polifónica de Juan Vásquez, anterior a 1560 , contrahechura probable de un pasaje de romance. La glosa del cantar "Si el pastorcico es nuevo" con que se inicia la segunda parte de la Recopilación de sonetos y villancicos (ed. H. Anglés, Barcelona, 1946, pp. 115-117) dice asi:

$$
\begin{aligned}
& \text {-Digas, el pastorcico, } \\
& \text { galán y tan pulido, } \\
& \text { ¿cúyas eran las vacas } \\
& \text { que pastan par del río? } \\
& \text {-Vuestras son, mi señora, } \\
& \text { y mío es el suspiro'. }
\end{aligned}
$$

Este texto plantea un problema interesante. Según nos dicen Galmés y Catalán ( $V R, 13,1953$, p. 77$)$, "el encuentro con la vacada... es muy frecuente en las baladas extranjeras de tema análogo, y de una de ellas pasó sin duda a nuestro romance, bien directamente, bien a través de un intermediario hispánico". La pregunta "cúyas eran las vacas...?" en la canción de Vásquez parece probar que el tema ya había pasado a un romance español para mediados del siglo xvi, y la respuesta "[de...] son, mi señora" nos está diciendo que en ese romance la pregunta partía ya de una mujer. No creo, pues, arriesgado suponer que el perdido romance contrahecho en la composición polifónica, contemporáneo del Dirlos juglaresco, fuera, al menos en parte, otro antecedente hispánico del romance tradicional de la Boda estorbada.

En cuanto a Gerineldo, Horrent considera que el texto del pliego suelto de 1537 no es fragmentario; la introducción y el desenlace del otro pliego antiguo y de tantas versiones orales le parecen ediciones posteriores; las versiones judeo-españolas que incorporan ambos elementos nada prueban, pues "la tradición de los sefardíes de Oriente es mucho menos pura de lo que suele pensarse" (p. $3^{87}$ ). La primera versión impresa "debe estar más cerca del romance original que las versiones orales de hoy" (p. 390); su mayor sencillez es deliberado hallazgo de su creador - "oublis de poète".

Horrent pasa así a una fundamental cuestión de principio. La teoría tradicionalista "sacrifica con demasiada facilidad al primer creador", aun reconociendo su existencia; pero no por desconocido deja de ser ese primer poeta, como todo poeta, quien ha plasmado en una forma

1 Cf. mi artículo "Sobre los textos poéticos en Juan Vásquez, Mudarra y Narváez", NRFH, 6 (1952), p. 52. Menéndez Pidal ha rectificado ahora su anterior afirmación de que el encuentro con el paje que lleva caballos precede al encuentro con la vacada: "La presencia de vacas en todas las versiones de[l] Dirlos tradicional no permite afirmar la prioridad de los caballos" (Cómo vive un romance, p. 59, nota). 
artística particular algo que no lo estaba antes. Su anonimato debe explicarse por "las circunstancias peculiares de la creación artística en la Edad Media y el destino dado a los romances" (p. 393, nota) "2.

Con acierto dice Horrent que los refundidores posteriores, por importantes que sean, no pueden compararse con el primer autor, puesto que "no persiguen la novedad en cuanto tal" (p. 392). Identifica con los refundidores de gestas y crónicas a los refundidores de romances: "La única diferencia... está en que en el primer caso el retoque se efectúa sobre el pergamino y tiene posibilidades de perpetuarse, mientras que en el segundo se queda en los labios, efímero y fugitivo" (p. 393). Olvida aquí Horrent que también los retoques hechos a los romances suelen perpetuarse, y que en muchas ocasiones afectan no sólo a los accidentes, sino a la esencia misma del texto. Las incontables fluctuaciones efímeras no tienen verdadera importancia; si la tienen, en cambio, en mayor o en menor medida, las modificaciones que logran imponerse y perdurar. No el proceder del refundidor individual (análogo quizá al del refundidor de gestas), sino el número y muchas veces la importancia de los retoques que subsisten, a través del espacio y del tiempo, hacen que la refundición influya mucho más hondamente en el carácter de los romances que en el de las canciones de gesta y las crónicas.

El Colegio de México.

Margit Frenk Alatorre

\section{VALLE-INCLAN Y UN HAI-KU DE BASHO}

Hemos visto cómo Valle-Inclán solía introducir en su obra versos de otros autores (Espronceda, Dario) para lograr diversos efectos o para criticar ya una tendencia literaria, ya un grupo humano ${ }^{1}$. Pero en ambos casos se trataba de poetas perfectamente accesibles y que gozaron hasta cierto momento de la predilección de Valle. Mucho menos claro nos resulta comprender cómo se puso en contacto con Basho y por qué lo utilizó. Me limitaré, pues, a indicar el hai-ku de que echó mano y a hacer algunas sugerencias, dejando para un investigador más afortunado el descubrimiento de los eslabones que no he podido hallar.

En Farsa y licencia de la Reina Castiza $a^{2}$ encuentro la siguiente apostilla escénica: "La patrulla calamucana, bajo la luna hace sig-zás, y el espejo de la fontana, al zambullirse de la rana, hace ;chás!". En 1922, Valle la distribuyó en estrofa ${ }^{3}$. Separando los tres últimos versos, nos queda (p. 44):

${ }^{2}$ Creo, sin embargo, que la razón fundamental de ese anonimato es la misma que hace anónimos, en su inmensa mayoría, los cantos populares de todos los países y de todas las épocas: el carácter relativamente impersonal de su creación, siempre sujeta en alto grado a un conjunto de materiales y procedimientos tradicionales.

${ }^{1}$ Cf. La elaboración artistica en "Tirano Banderas", El Colegio de México, México, 1957, pp. 102-103, notas 30 y 31 .

- La Pluma, Madrid, año 1 , núm. 3, agosto de 1920, p. 111.

$\because$ Edición de Artes de la Ilustración, Madrid, 1922, pp. 43-44. Lo mismo puede 